\title{
Quantifying the Impact of Connection Policy on Distributed Generation
}

\author{
A. Keane, Student Member, IEEE, E. Denny, Student Member, IEEE, M. O’Malley, Senior Member, IEEE
}

\begin{abstract}
Increasing connections for distributed generation (DG), and in particular wind generation, are being sought in power systems across the world. These increased applications present a significant challenge to the existing connection policies of distribution network operators. In particular, non firm access to the network has been proposed as a method to increase the penetration of DG. The impact of the connection policies arising from non firm access are investigated in detail here. The Irish system is used as a case study, and with reference to the available energy resource and network parameters, the costs and benefits of DG are determined under a number of planning policies. The costs and benefits assessed include connection and cycling costs along with emissions, capacity value and fuel bill saving. It is shown that a significant increase in the net benefits of DG is gained if the appropriate connection policy is utilised from the outset and conversely that significant costs are incurred if ad hoc policies are employed. Furthermore, it is shown that non firm access has the scope to facilitate a significant extra amount of DG capacity.
\end{abstract}

Index Terms-Power distribution planning, Power system economics, Linear programming, Energy resources, Dispersed storage and generation, Wind power generation, Costs.

\section{INTRODUCTION}

D ISTRIBUTED generation (DG) can be defined as smallscale generation, which is not directly connected to the transmission system and is not centrally dispatched. The connection of DG has led to a change in the characteristics of the network. If increasing levels of generation are to be accommodated, then there should be a change of thinking regarding the planning and design of the distribution network. Wind generation is the fastest growing form of DG, with significant penetrations connected already in many countries [1].

The traditional approach to DG planning, on a first come first served basis, is becoming outdated as the volume of applications increase. Indeed, in some countries it has already been replaced [2]. Another traditional approach to DG planning has been to permit access to the distribution network only on a firm basis. The amount of firm access granted under the connection agreement to a distributed generator is the level of output at which they can always operate without violating any of the $\mathrm{N}-1$ constraints on the network. The impact of these technical

This work has been conducted in the Electricity Research Centre, University College Dublin, which is supported by ESB Networks, ESB Powergen, ESB National Grid, Cylon, Viridian, the Commission for Energy Regulation and Airtricity. A. Keane is funded by Sustainable Energy Ireland through a postgraduate research scholarship from the Irish Research Council for Science Engineering and Technology. A. Keane, E. Denny and M. O'Malley are with the School of Electrical, Electronic \& Mechanical Engineering, University College Dublin, Dublin 4, Ireland (Ph: +353 (0)1 7161857; e-mail: andrew.keane@ee.ucd.ie; eleanor.denny@ee.ucd.ie; mark.omalley@ucd.ie) constraints on the penetration of DG has been demonstrated in [3] [4], along with the network sterilisation effect which can occur if DG capacity is not allocated with full account of these constraints [5], [6].

Non firm access refers to output greater than the firm amount, at which generators may be allowed operate dependent on the load and generation levels throughout the year. Non firm access utilises some form of active control to manage the constraint breaches. Previous work has shown the scope for the optimisation of plant mix for the maximisation of energy [7]. There are a number of costs and benefits associated with the various types of DG. Previous work has attempted to quantify the net benefits of DG [8], where a number of benefits such as reduced losses and voltage profile were assessed.

This paper seeks to assess the impact of a high penetration of DG, with account taken for the likely DG plant mix. It does not attempt to place an upper limit on the amount of DG that can be feasibly connected to an entire distribution network. The impact of DG on the transmission system is not included here. The dispatch model used is a single busbar system and the aim of this paper is to assess the impact of DG on the distribution system. In particular, the voltage constraint is the dominant constraint and can be managed on a non firm basis. The implementation of non firm management of constraints requires a change in the traditional connection policy of network operators. Furthermore, it leads to a change in the optimal allocation of DG as calculated using previously established methodologies [5] [6] [4]. It is issues such as these, arising out of the change in connection policy, that lead to a change in the costs and benefits of DG. These costs and benefits are quantified here to assess the impact of connection policy on DG and more specifically to assess the impact of non firm access.

The Irish system is taken as a case study. Drawing on estimates of the Irish renewable energy resource [9] and system data [10] [11], the impact of different connection policies for DG is assessed, quantifying in each case the costs and benefits that result. The importance of a clear set of objectives at the start of the connection process is highlighted and it will be demonstrated that significant costs can be incurred through the employment of ad hoc methodologies. The optimal firm allocation of the available energy resources may not lead to the optimal non firm allocation at a later stage. This paper addresses the question of which policy is best for facilitating higher penetrations of DG. Different individual allocations impact on the costs and benefits of DG and it is these costs and benefits which are quantified here under a number of connection policies. 
Section II describes the methodology used to determine the impact of various connection policies. Results and discussion are given in Section IV illustrating the impact that the connection policy has on the cost and benefits of DG. Comparisons between different cases are given. Conclusions are given in Section V.

\section{Methodology}

The optimisation of access to the distribution network has been demonstrated for a single section of distribution network in [5] and [7]. Here the integration of DG across the whole system is investigated. The distribution network is optimised using previously established methodologies. These methods are applied under three different connection policies and the costs and benefits are then quantified to determine the impact of connection policy on DG and more specifically on wind generation.

\section{A. Objective Function}

The objective of the methodology is to maximise the amount of DG energy per euro of investment by making best use of the existing network assets and available energy resource. This is done subject to the technical constraints on the network. The optimisation problem is formulated as a linear program, with the amount of constraint breaches that arise with non firm access taken into account. The load factors of each energy resource are included, meaning that the available capacity is allocated based on the amount of energy that is delivered. The objective function is given in Equation (1).

$$
J=\sum_{j=1}^{M} \sum_{i=1}^{N} \frac{P_{\text {Avail } j} \text { Plant }_{i j} L F_{j}}{\text { ConnCost }_{i j} \nu_{i}}
$$

Where $P_{\text {Avail }}$ is the $j$ th available energy resource. Plant ${ }_{i j}$ are the control variables representing the fraction of $P_{\text {Avail } j}$ allocated to the ith bus. $L F_{j}$ is the load factor of the $j t h$ energy resource. $\nu_{i}$ gives the total voltage sensitivity of the $i t h$ bus to power injections at all other buses. ConnCost ${ }_{i j}$ is the connection costs of the $j t h$ energy resource at the $i t h$ bus. $\mathrm{M} \& \mathrm{~N}$ are the number of energy resources and buses respectively. The geographical dispersion of DG impacts the connection costs. The connection costs of each resource to each bus are determined and are minimised in the objective function. The objective function is maximised with respect to the technical constraints in Equations (3), (4), (5) and (6), given in the Appendix [5]. These constraints limit the DG allocation based on the technical characteristics of the network.

This objective function in Equation (1) maximises the energy harvesting capability of the existing network. It maximises it with respect to the technical constraints. The available capacity is a valuable asset and should be optimally utilised. This objective function maximises the energy harvested from the available capacity by using the load factors of the generation. Load factors express the energy output of a generator as a fraction of the maximum possible energy output that is produced by a generator in a year. In addition, it is now assumed that non firm management of the voltage constraint is permitted, thus allowing an increase in the permissable capacity. This non firm capacity is optimised through the use of bus voltage sensitivities $\nu_{i}$. These sensitivities are included in the objective function as a means of reducing the occurrence of overvoltage conditions, thereby reducing the amount of energy curtailed and enabling easier congestion management on the distribution network.

\section{B. Non Firm Constraint Management}

The local network constraints have previously been analysed in detail in [3]. The voltage constraint, given in Equation (7) is the key constraint in the analysis. Voltage rise is one of the dominant technical constraints on DG. The assessment of the voltage constraint at a $\mathrm{N}-1$ peaking condition can present a significant barrier to further penetration of DG. While infrequent, it is important for the operation of the system that the voltage stays within its limits. A number of voltage control techniques have been proposed to mitigate the voltage rise effect [12] [13]. These techniques along with others facilitate non firm management of the voltage constraint. The short circuit level may be dominant in more urban areas. However, active management of fault levels is some way off and is likely to be very expensive [14]. Hence, it is non firm management of the voltage constraint which is considered here.

\section{Network Analysis}

A number of representative samples of the distribution network were analysed. These sections were chosen based on their geographical location and also on their characteristics (i.e. rural or semi urban). Likely energy resource portfolios were associated with each section. Drawing on the methods developed in [5] and [7], each section was analysed and the optimal allocation of the energy resources was determined for 3 cases.

- Firm

- Non Firm

- Firm + Non Firm

The first case is the base case of the maximum firm allocation optimised on a $\mathrm{MWh} / €$ basis, i.e. the amount of energy per euro of connection costs is maximised. The voltage constraint in Equation (7) is included and the voltage sensitivities $\nu_{i}$ are removed from the objective function. The second case refers to the maximum non firm access permitted, where the voltage sensitivities $\nu_{i}$ are utilised in the objective function to reduce the instances of overvoltage. The third case examined is the case where firm access is initially only permitted and then non firm access is permitted at a later stage. These two non firm cases are optimised on a MWh/€kV basis as shown in Equation (1).

The implementation and stages of the methodology are shown in Figure 1. It is seen that based on the technical constraints the allocations under the two objectives are calculated. The firm allocation (MWh/€) is fed as a constraint into the non firm allocation, which yields the firm + non firm allocation. Each of the three allocations are then simulated on the distribution network over a year using load flow analysis. 
From these load flow analyses, the instances of curtailment are determined and used to appropriately manipulate the profiles used in the dispatch model. Based on analysis of the Irish distribution network and energy resource, the allocations are scaled to reflect both the likely DG penetrations of each resource and the overall characteristics of the Irish distribution network. The dispatch model is run based on these scaled allocations for the same year and the costs and benefits of each of the three connection policies are calculated based on the results of this.

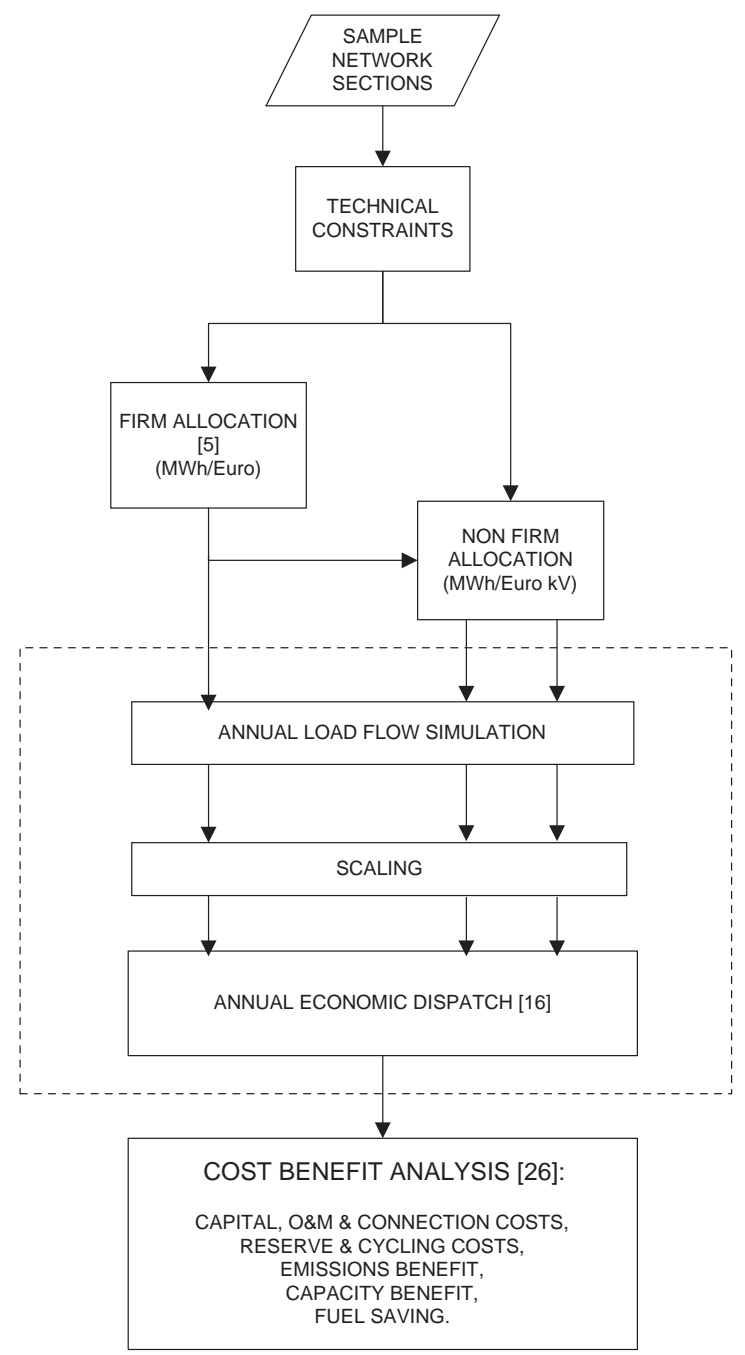

Fig. 1. Methodology

\section{Annual Simulations}

1) Load Flow Simulation: The allocations of DG capacity on the system are determined and the annual energy output for each DG resource is ascertained. For the firm case, the annual energy output is determined using actual historical data series from [15]. For the non firm cases, over the year, constraint breaches will occur at times of high generation and low load. Annual simulations are carried out for the network sections to determine the time and magnitude of energy curtailment. These simulations consist of load flow calculations carried out for half hourly data. The data included in the simulations includes active and reactive load and generation profiles for each of the energy resources, along with data on frequency of $\mathrm{N}-1$ outages and the sending voltage at the transmission station.

When constraint breaches occur due to overvoltage, the level of curtailment is calculated using the formula shown in Equation (2).

$$
P_{\text {Curtail } i}=\frac{V_{i}-V_{\text {Max }}}{2 \nu_{i}} i \forall N .
$$

Where $P_{\text {Curtaili }}(\mathrm{MWh})$ is the amount of energy that is curtailed over a half hour period at the ith bus. $V_{i}$ and $V_{\text {Max }}(\mathrm{kV})$ are the voltage at the ith bus and the maximum permissable voltage respectively. $\nu_{i}$ is the voltage sensitivity (kV/MW) of the ith bus and $\mathrm{N}$ is the number of distribution buses. $\nu_{i}$ is calculated for each bus drawing on the analysis used in [5]. This curtailment method results in the least amount of energy being curtailed, by curtailing the generator who has the highest voltage sensitivity at that bus. The annual load flow simulation yields the amount of energy curtailed over the year, which in turn gives modified generation profiles, which can then be used in the economic dispatch model.

2) Dispatch Model: A dispatch model of the full Irish system was developed which generates least-cost dispatches using a linear programming formulation which co-optimises generators' operating and reserve levels on a half hourly basis (discussed in detail in [16] and [17]). Given that renewable energy resources must receive priority dispatch in Ireland [18], it is assumed that the DG resources bid zero into the model and are dispatched according to their actual energy output. It is assumed that the DG resources do not provide reserve. The conventional generators are then dispatched according to their bid prices for energy and reserve on a least cost basis.

The dispatch model was run for each half hour for one year and the generation and reserve operating levels for each generator were determined given the DG installed capacities in each of the three connection policy scenarios. As described above, the profiles are then manipulated to curtail the DG output at times of high output and low load, which correspond to the times of curtailment recorded from the annual load flow simulation. The chosen test year is 2007 with the assumed load and conventional plant mix given in [19]. These dispatches were then used to calculate the costs and benefits of the three different connection policies.

\section{E. Costs and Benefits}

The capital cost of wind generation is assumed to be $€ 900,000$ per MW with an operation and maintenance cost of $€ 45,000$ per MW per year with a term of 15 years and a discount rate of $7.5 \%$ [20]. The connection costs are variable per $\mathrm{km}$ of line and are taken to be $50,000 € / \mathrm{km}$.

An increase in the penetration of variable wind generation on a system results in an increase in uncertainty on the electricity system as wind generation is relatively unpredictable and non-dispatchable. This results in a requirement to carry additional reserve capacity in order to maintain system security [21], and is a cost imposed on the system by increased wind 
generation. A DG technology which can be considered to be dispatchable, such as biomass, does not impose an additional reserve requirement on the system. The additional reserve requirement for the installed wind generation under the three connection policies was based on [22].

Conventional thermal units are designed to be at their most efficient when online and running at a stable load. In general, units are optimised for continuous rather than cyclical operation and when operating in their normal range can operate for relatively long periods with relatively low risk and loss of equipment life [23]. An increase in the cycling of conventional units, as a result of an increase in variable generation on the system, can result in increased wear and tear on the components of the machine and result in a shortening of the life span of the unit [23]. Cycling costs are high and can range from $€ 200$ to $€ 500,000$ (including fuel cost) per single on-off cycle depending on the type of unit [23]. Thus, an increase in cycling as a result of an increase in the penetration of variable generation on the system can have a significant impact on system cycling costs and are therefore included here.

Despite being variable, wind generation and the other DG resources have a capacity benefit. The extent to which a technology can substitute for conventional generation is given by the capacity value of that technology and for non dispatchable technologies, the capacity value decreases with increasing installed capacity [24]. An increase in the penetration of DG results in a reduced requirement for new conventional generation development. Thus, the capacity benefit of DG can be deemed to be the saved cost of building and maintaining conventional thermal generation in its place. The capacity credit for Ireland ranges from $41 \%$ at low wind penetrations to $20 \%$ at high wind penetrations [24]. It is assumed that any new conventional generation built in Ireland will be gas fired, with a capital cost of $€ 687,000$ per MW installed and operation and maintenance costs of $€ 50,000$ per MW per year [24], [25].

The operation of renewable generation can result in a reduction in the operation of some of the thermal units on the system. The carbon dioxide $\left(\mathrm{CO}_{2}\right)$ and sulphur dioxide $\left(\mathrm{SO}_{2}\right)$ emissions of a thermal unit depend on the carbon and sulphur content of the fuel respectively and the quantity of fuel burnt. Thus, a reduction in the output of a thermal unit, as a result of an increase in DG generation, can lead to a reduction in $\mathrm{CO}_{2}$ and $\mathrm{SO}_{2}$ emissions [16]. This is a significant benefit of increased DG penetration. Nitrogen Oxide $\left(\mathrm{NO}_{\mathrm{x}}\right)$ emissions are more complicated and are effected by the flame temperature, residence time, oxygen concentration etc. Thus, it is not necessarily the case that a reduction in output leads to a reduction in $\mathrm{NO}_{\mathrm{x}}$ emissions, and an increase in variable generation could in fact result in an increase in system $\mathrm{NO}_{\mathrm{x}}$ emissions [16].

A reduction in the output of thermal units on the system can result in a reduction in the quantity of fuel burnt. Thus, an increase in DG can result in a system fuel saving. This is a significant benefit of increased DG generation, and in particular for wind generation which has a zero fuel cost. All of the above costs and benefits were calculated for each of the three connection policy allocations [26].

\section{Test Systems And Energy Resource}

\section{A. Test Systems}

In Ireland, DG is typically connected at $38 \mathrm{kV}$ or by direct feed to the $38 \mathrm{kV} / \mathrm{MV}$ station on the MV network $(10 \mathrm{kV}$ or $20 \mathrm{kV}$ ). Voltage rise tends to be the dominant constraint due to the network in Ireland, which outside the main cities is typically a weak rural network with a large amount of conductor. A weak network means a network with a low short circuit level or fault level. Ireland has a rich wind resource, especially along its western coastline. In addition to the wind resource, there is limited scope for small scale hydro and landfill gas along with significant amounts of biomass in the form of industry and forest residue [9]. Drawing on [9] and [27], estimates of the Irish renewable energy resource and its geographical dispersion are used to assess the successful integration of DG on a system wide basis.

Five test systems are chosen as a representative sample of the types of network encountered on the Irish distribution network where generation will seek to connect. Load flow and short circuit analysis is used to determine and formulate the various constraints and factors used in the optimisation. Load values and network parameters for each section were obtained from ESB National Grid [10] and ESB Networks [11]. Figure 2 shows the likely future per county distribution of installed wind power per county, reproduced from [22]. The five network sections were selected from along the western coastline and also in the southeast of the country. It is evident from Figure 2 that it is in these locations that connections of DG, and in particular wind generation, will and are being sought.

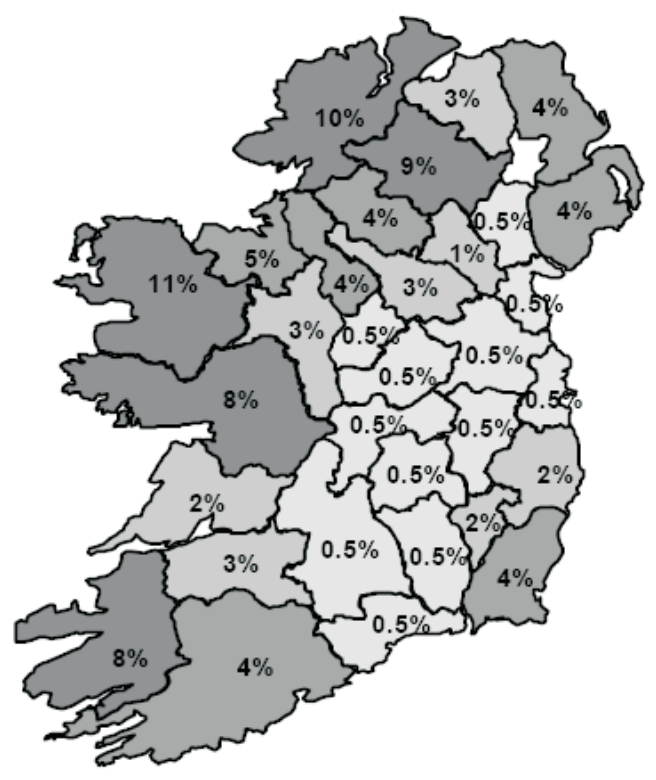

Fig. 2. Future per-county distribution of installed wind power capacity in percent

The network sections were also selected based on their characteristics and structure from network data available [11]. They represent the types of network encountered on the Irish distribution network, from voltage constrained rural networks 
to more urban networks where voltage is less of a problem and short circuit level can become significant.

\section{B. Energy Resource}

A representative energy resource portfolio is drawn up for each network section based on its geographical location and with reference to Figure 2 and [9]. Using typical values for the load factor of each type of generation [28], these resources are incorporated into the objective function (1). Each network section has its own distinct assumed energy resource. Table I shows the total assumed energy resource and load factors across the five representative network sections.

TABLE I

ASSUMED ENERGY RESOURCE (MW)

\begin{tabular}{|c|c|c|}
\hline Energy Source & Capacity & LF \\
\hline \hline Wind & 138 & 0.35 \\
Biomass & 35 & 0.85 \\
LFG & 12 & 0.76 \\
Hydro & 6 & 0.32 \\
\hline Total & 191 & - \\
\hline
\end{tabular}

\section{RESUlTS \& DisCUSSION}

\section{A. Energy Allocations}

The allocations for the five network sections were determined under the three connection policies using the methodology described in Section II and are shown in Table II. Given their significantly higher load factor, any available biomass and landfill gas (LFG) are allocated the available firm capacity first. As a result, there is very little difference, between their firm and non firm capacities, leading to the conclusion that when a maximisation of energy strategy is followed, forms of generation with higher load factors are largely independent of the connection policy as they will always be connected first. The small scale hydro generation also has very little difference between its firm and non firm allocation, but this is due to the limited resource available. When these factors are combined with the high wind resource, it is evident that it is the costs and benefits of wind generation that are affected by the connection policy and it is wind generation therefore that is the focus of the results in this paper.

Initially, it is assumed that there is no generation previously connected. For the firm + non firm case, it is assumed that the maximum firm capacity has been connected. The non firm capacity is then allocated on top of the existing firm capacity. Two out of the five network sections analysed were not voltage constrained. These network sections were located in less rural areas, i.e. with higher load and short circuit levels. It was found that the short circuit level was the binding constraint in these cases and therefore non firm voltage access did not yield any further generation capacity. The other three network sections were all voltage constrained and had a rich wind resource, as would be typical all along the western coastline of Ireland. In these cases, non firm access yielded a significant amount of extra capacity. However, for one of the sections no difference was found between the two non firm connection policies. In this case, it was found that the constraint of the existing firm access did not affect the optimal non firm allocation. Although in the other two voltage constrained network sections, the existing firm allocation did affect the non firm allocation, resulting in higher connection costs and more curtailment of energy.

TABLE II

ALlocations Under THE THREE DifFERENT CONNECTION POLICIES FOR THE FIVE NETWORK SECTIONS (MW)

\begin{tabular}{|l|c|c|c|c|}
\hline & & Firm & Non Firm & $\begin{array}{c}\text { Firm }+ \\
\text { Non Firm }\end{array}$ \\
\hline \hline \multirow{5}{*}{ Installed MW } & Wind & 48.6 & 94 & 94 \\
& Biomass & 34.4 & 35 & 35 \\
& LFG & 12 & 12 & 12 \\
& Hydro & 5.0 & 5.8 & 5.8 \\
\hline \multirow{5}{*}{ Energy GWh } & Wind & 153 & 291 & 289 \\
& Biomass & 259 & 264 & 264 \\
& LFG & 80 & 80 & 80 \\
& Hydro & 14 & 16.5 & 16.5 \\
\hline & Wind & 4.45 & 8.55 & 10.35 \\
& Biomass & 3.10 & 2.775 & 3.1 \\
& LFG & 2.025 & 2.025 & 2.025 \\
& Hydro & 1.35 & 1.85 & 1.85 \\
\hline
\end{tabular}

From Table II it is evident that given a large wind resource, non firm access has the potential to facilitate much higher penetrations than firm access. Nonetheless, the question arises of what is the optimal way of providing non firm access. The allocations shown in Table II are only for five network sections.

To quantify fully the effect of the connection policy of DG on the whole system, these allocations were scaled up based on the total Irish distribution network and the likely penetrations and locations of renewable energy [9] [27] [24] [11]. The scaled allocations for DG under the three connection policies were determined to facilitate the quantification of the costs and benefits of DG on a system wide basis. The installed capacities and the annual energy outputs, based on actual output data series [15] and the total curtailed energy, are given in Table III.

Figure 3 shows the output profile for each of the four allocated DG types over a single day in March on a single section of network. This day is illustrated as it is an example of a day of particularly high wind generation when the output had to be curtailed in the non-firm case.

\section{B. Wind Generation Development Costs}

The total connection costs for wind under the three connection policies across the whole system are given in Table IV. A considerable saving in connection costs is made when a non firm connection policy is pursued from the outset. In some cases, the extra non firm capacity can share the existing 
TABLE III

SCALED Allocations UNDER THE THREE DiFFERENT CONNECTION POLICIES FOR THE WHOLE SYSTEM(MW)

\begin{tabular}{|c|c|c|c|c|}
\hline & & Firm & Non Firm & $\begin{array}{c}\text { Firm + } \\
\text { Non Firm }\end{array}$ \\
\hline \hline \multirow{3}{*}{ Installed MW } & Wind & 655 & 1392 & 1392 \\
& LFG & 96 & 96 & 410 \\
& Hydro & 64 & 77 & 77 \\
\hline \multirow{3}{*}{ Energy GWh } & Wind & 2065 & 4333 & 4302 \\
& Biomass & 3018 & 3089 & 3089 \\
& LFG & 639 & 639 & 639 \\
& Hydro & 184 & 221 & 221 \\
\hline
\end{tabular}

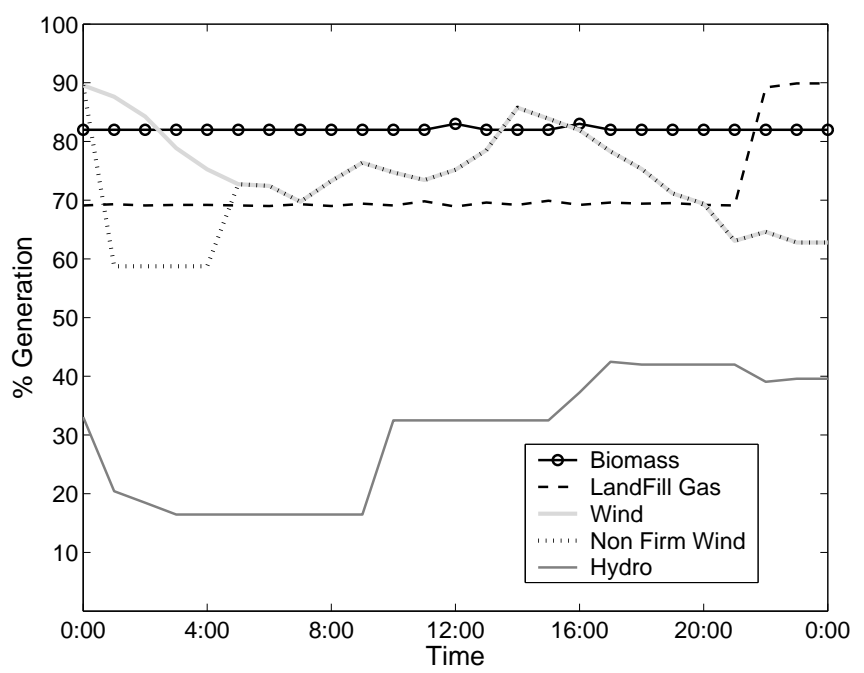

Fig. 3. Output of DG generators as a percentage of their installed capacity on a sample day

connection line, but it is seen from the results that on other occasions new connection lines must be built.

TABLE IV

Connection Costs For Wind Generation

\begin{tabular}{|l|c|c|}
\hline Connection Policy & Installed MW & Connection Cost \\
\hline \hline Firm & 655 & $€ 61,300,000$ \\
\hline Non Firm & 1392 & $€ 128,000,000$ \\
\hline Firm + Non Firm & 1392 & $€ 156,800,000$ \\
\hline
\end{tabular}

\section{System Costs \& Benefits}

The DG output levels for each technology under the three connection policy scenarios for each day of the sample year is determined from the DG generation profiles from [15]. These operating levels were then bid into the dispatch model with a bid price of zero, ensuring priority dispatch. The resulting dispatches were then analysed to determine the costs and benefits of each of the three connection policy approaches.
The additional reserve requirement for the system with increased wind penetration is taken from [22] and the cost incurred is valued at $€ 1.15$ per MW per hour [29]. However, given that the installed capacity is the same in both non firm cases, the additional reserve costs are unaffected by the connection policy and are the same in both cases.

In order to calculate the cycling cost associated with each of the three allocations, all of the starts and ramping excursions over the year were counted and were converted into equivalent hot starts [23]. The cycling cost of each hot start was then calculated according to the type of generator in question. The additional cycling costs over zero installed wind capacity, under each of the connection policies is given in Table V. It can be seen that significant extra cycling costs are incurred as more wind generation is installed on the system.

TABLE V

Additional Cycling Costs With Wind Generation

\begin{tabular}{|l|c|}
\hline Connection Policy & Additional Cycling Cost \\
\hline \hline Firm & $€ 2,240,600$ \\
\hline Non Firm & $€ 9,413,700$ \\
\hline Firm + Non Firm & $€ 8,860,100$ \\
\hline
\end{tabular}

The dispatch model was run for each day of the test year and the resulting dispatches were then used to calculate the $\mathrm{CO}_{2}, \mathrm{SO}_{2}$ and $\mathrm{NO}_{\mathrm{x}}$ emissions for each of the conventional generators [16]. Since the wind generation displaced mostly marginal oil fired plants and gas plants it was seen to give a saving across each of the three emissions. Table VI below shows the emission savings across the year compared to a no wind case. The carbon dioxide emissions are valued at $€ 30$ per ton, and the $\mathrm{SO}_{2}$ and $\mathrm{NO}_{\mathrm{x}}$ emissions at $€ 150$ and $€ 3000$ per ton respectively [30]. Given the magnitude of the $\mathrm{CO}_{2}$ emissions when compared to the other emissions, the price of carbon dictates the benefits accruing from increased wind penetration. An emissions factor which accounted for the price of the emissions was included in the bid price of each generator in the dispatch model.

TABLE VI

EMISSIONS SAVINGS (IN TONS) WITH WIND GENERATION

\begin{tabular}{|l|c|c|c|c|}
\hline Connection & $\mathrm{CO}_{2}$ & $\mathrm{SO}_{2}$ & $\mathrm{NO}_{\mathbf{x}}$ & Benefit $€$ \\
\hline \hline Firm & $1,035,400$ & 2,185 & 1,147 & $34,830,000$ \\
\hline Non Firm & $2,189,700$ & 3,659 & 1,965 & $72,136,000$ \\
\hline Firm + Non Firm & $2,181,300$ & 3,659 & 1,959 & $71,863,000$ \\
\hline
\end{tabular}

The additional wind generation on the system also provides a saving in fuel consumption as thermal units are displaced. Table VII shows the fuel savings with increased wind generation. The fuel prices given in Table VII were also used in the dispatch of the generators [26].

\section{Net Benefits}

The costs and benefits above were combined and the net benefits of each connection policy were determined. It was 
TABLE VII

FuEl SAVINGS IN PETAJOULES With Wind GENERATION

\begin{tabular}{|l|c|c|c|c|c|}
\hline Fuel Type & Gas & Coal & Peat & Oil & Benefit $€$ \\
Price $€ / G J$ & 4.16 & 2.15 & 3.14 & 4.13 & \\
\hline \hline Firm & 8.86 & 0.02 & 0.953 & 4.45 & $58,273,000$ \\
\hline Non Firm & 19.99 & 0.22 & 2.25 & 7.63 & $122,240,000$ \\
\hline Firm + Non Firm & 19.87 & 0.22 & 2.25 & 7.63 & $121,740,000$ \\
\hline
\end{tabular}

found that although the benefits outweighed the costs under all three connection policies there was a significant difference in the net benefits. Table VIII shows the net benefits of each of the connection policies.

TABLE VIII

NeT BENEFITS OF WIND GENERATION (IN €M)

\begin{tabular}{|l|c|c|c|c|}
\hline & Cap. (MW) & Total Cost & Total Benefit & Net Benefit \\
\hline \hline Firm & 655 & 932 & 1,127 & 191 \\
\hline Non Firm & 1392 & 2,019 & 2,347 & 328 \\
\hline Firm+NonFirm & 1392 & 2,043 & 2,335 & 293 \\
\hline
\end{tabular}

As is evident from Table VIII, while the two non firm policies both result in the same installed capacity of generation, the costs and benefits of wind generation show significant differences. There is a significant increase of $12 \%$ in net benefits under non firm connection than under a firm and then non firm scenario for the same level of installed wind. The increases in net benefits results from the different pattern on connected generation across the buses, which leads to altered connection costs and curtailed energy, which in turn impacts upon a number of the costs and benefits as detailed above.

It is clear that the connection policy affects the energy output and connection costs and furthermore that this has a considerable knock on effect on system costs and benefits such as cycling costs, emissions and fuel use. It has also been shown that as some costs, such as the additional reserve cost and the capital cost, are dependent on the capacity of the plant installed, they are unaffected by the non firm connection policy employed.

\section{CONCLUSION}

The impact of connection policy on DG for a number of connection policies has been quantified. The utilisation of the appropriate connection policy from the outset has been shown. There is a considerable effect on the costs and benefits of DG, which has been determined. It has been shown that an equal amounts of DG capacity connected can have significant differences in costs and benefits, dependent on the connection policy. The advantages of a clear objective at the outset of the DG planning process has been clearly shown. In addition, the significantly higher penetration of DG facilitated by non firm access to the distribution network has been demonstrated.

\section{APPENDIX}

Thermal Constraint

$$
I_{i}<I_{i}^{\text {Rated }} i \forall N \text {. }
$$

Where $I_{i}$ is the current flowing from generator $i$ to bus $i$, $I_{i}^{\text {Rated }}$ is the maximum rated current for the line between each generator and its corresponding bus.

\section{Short Circuit Level}

$$
\sum_{j=1}^{N} \delta_{j T x} P_{D G j}+\alpha_{T x} \leq S C L_{\text {Rated }} .
$$

Where $\delta_{j T x}$ is the dependency of the SCL at the transmission station to power injections at bus $j . \alpha_{T x}$ is the initial SCL at the transmission bus with no generation present and $S C L_{\text {Rated }}$ is the maximum permissable short circuit level as laid down in the distribution code.

\section{Short Circuit Ratio}

$$
P_{D G i}-0.1 \cos (\phi) \sum_{j=1}^{N} \delta_{j i} P_{D G j} \leq 0.1 \cos (\phi) \alpha_{i} i \forall N .
$$

Where $\cos (\phi)$ is the power factor at the generator.

\section{Transformer Rating}

$$
\sum_{i=1}^{N}\left(P_{D G i}-P_{L D i}\right) \leq P_{\text {TrafoCap }}
$$

Where $P_{\text {TrafoCap }}$ refers to the rating of the transformer and $P_{L D i}$ is the minimum load level at the $i$ th bus.

Voltage Rise

$$
\sum_{j=1}^{N}\left(\mu_{i j} P_{D G i j}+\nu_{i j} P_{L D i j}\right)+\beta_{i} \leq V_{\max i} i \forall N .
$$

Where $\mu_{j i}$ and $\nu_{j i}$ refer to the dependency of the voltage level at bus $i$ on power injections and load at bus $j$ respectively, $\beta_{i}$ refers to the initial voltage level at the $i$ th bus with no generation.

\section{ACKNOWLEDGMENT}

The authors gratefully acknowledge ESB National Grid and ESB Networks for the data provided along with their colleagues in the Electricity Research Centre for their help with this work. 


\section{REFERENCES}

[1] European Wind Energy Association, "A blueprint to achieve 12\% of the world's electricity from wind power by 2020," Tech. Rep., 2005. [Online]. Available: http://www.ewea.com/

[2] Commission for Energy Regulation. (2004) Group processing approach for renewable generator connection applications. [Online]. Available: http://www.cer.ie/

[3] A. Keane and M. O'Malley, "Impact of distribution network constraints on distributed generation capacity," in Proc. of 40th International Universities Power Engineering Conference, Cork, 2005.

[4] A. R. Wallace and G. Harrison, "Planning for optimal accommodation of dispersed generation in distribution networks," in CIRED 17th International Conference on Electricity Distribution, Barcelona, May 2003.

[5] A. Keane and M. O'Malley, "Optimal allocation of embedded generation on distribution networks," IEEE Trans. Power Syst., vol. 20, no. 3, pp. 1640-1646, Aug. 2005.

[6] P. N. Vovos, G. Harrison, A. Wallace, and J. Bialek, "Optimal power flow as a tool for fault level-constrained network capacity analysis," IEEE Trans. Power Syst., vol. 20, no. 2, pp. 734-741, May 2005.

[7] A. Keane and M. O'Malley, "Optimal distributed generation plant mix with novel loss adjustment factors," in IEEE PES General Meeting, Montreal, June 2006

[8] P. Chiradeja and R. Ramakumar, "An approach to quantify the technical benefits of distributed generation," IEEE Trans. Energy Conv., vol. 19, no. 4, pp. 764-773, Dec. 2004.

[9] “Total renewable energy resource in Ireland," ESBI \& ETSU, Tech. Rep., 1997.

[10] (2005) ESB National Grid system information. [Online]. Available: http://www.eirgrid.com/

[11] (2005) ESB Networks infrastructure. [Online]. Available: http: //www.esb.ie/esbnetworks/

[12] C. Hird, H. Leite, N. Jenkins, and H. Li, "Network voltage controller for distributed generation," IEE Proc.-Gener. Transm. Distrib., vol. 151, no. 2, pp. 150-156, Mar. 2004.

[13] J. Hill, V. Thornley, C. Barbier, A. Maloyd, and A. Oliver, "Innovative voltage control techniques for optimum connection of renewable and intermittent generation to distribution networks," in Proc. of 40th International Universities Power Engineering Conference, Cork, 2005.

[14] KEMA, "The contribution to distribution network fault levels from the connection of distributed generation," Department of Trade \& Industry UK, Tech. Rep. DG/CG/00027/00/00, May 2005.

[15] (2006) All-Island Modelling Project. [Online]. Available: http: //www.allislandproject.org

[16] E. Denny and M. O'Malley, "Wind generation, power system operation, and emissions reduction," IEEE Trans. Power Syst., vol. 21, no. 1, pp. 341-347, Feb. 2006

[17] R. Doherty, G. Lalor, and M. O'Malley, "Frequency control in competitive electricity market dispatch," IEEE Transactions on Power Systems, vol. 20 , no. 3, pp. 1588-1596, 2005.

[18] Directive 2001/77/EC of the European Parliament and of the Council, "The promotion of electricity produced from renewable energy sources in the internal electricity market," 2001. [Online]. Available: http://www.europa.eu.int

[19] Transmission System Operator Ireland, "Generation adequacy report: 2006 - 2012," Available: www.eirgrid.com, 2005.

[20] European Wind Energy Association, "Wind power economics," Available: http://www.ewea.com, 2006.

[21] L. Soder, "Reserve margin planning in a wind-hydro-thermal power system," IEEE Transactions on Power Systems, vol. 8, pp. 564-571, 1993.

[22] R. Doherty and M. O'Malley, "New approach to quantify reserve demand in systems with significant installed wind capacity," IEEE Transactions on Power Systems, vol. 20, no. 2, pp. 587-595, 2005.

[23] S. Lefton, P. Besuner, and G. Grimsrud, "Understand what it really costs to cycle fossil-fired units," Power, vol. 141, no. 2, pp. 41-42, 1997.

[24] R. Doherty, H. Outhred, and M. O'Malley, "Establishing the role that wind may have in future generation portfolios," IEEE Transactions on Power Systems (in press), 2006.

[25] Commission for Energy Regulation Ireland, "Best new entrant price 2006 - CER/05/110," Available: www.cer.ie, 2005.

[26] E. Denny, G. Bryans, J. FitzGerald, and M. O'Malley, "A quantitative analysis of the net benefits of grid integrated wind," in IEEE PES General Meeting, Montreal, June 2006.
[27] R. Doherty, "High level assessment of suitable generation portfolios for the all-island system in 2020," All Island Grid Study WorkStream 2A, Tech. Rep., May 2006. [Online]. Available: http: //www.dcmnr.gov.ie/Energy/

[28] (2005) British Wind Energy Association. [Online]. Available: http: //www.bwea.com/energy/

[29] ESB National Grid (Eirgrid), "Statement of charges and payments for ancillary services providers 2005," www.eirgrid.ie, 2005.

[30] US Environmental Protection Agency, "Acid rain program," Available: http://www.epa.gov, 2006.

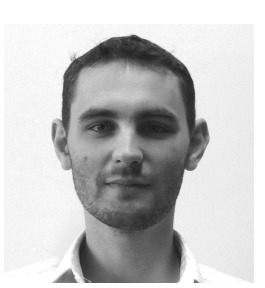

Andrew Keane (S'04) received a B.E. degree in electrical engineering from University College Dublin in 2003. He is currently conducting research for a Ph. D. degree in the Electricity Research Centre, University College Dublin with research interests in power systems planning, distributed generation and distribution networks.

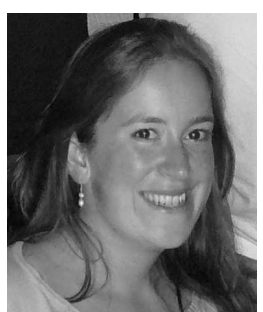

Eleanor Denny (S'04) received a B.A. degree in Economics and Mathematics and a M.B.S. degree in Quantitative Finance from University College Dublin. She is currently studying for a Ph. D. degree in the Electricity Research Centre, University College Dublin with research interests in the economics of wind generation.

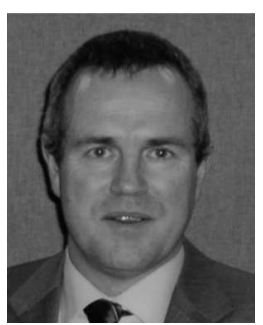

Mark O'Malley (S'86-M'87-SM'96) received B.E. and $\mathrm{Ph}$. D. degrees from University College Dublin in 1983 and 1987, respectively. $\mathrm{He}$ is currently the Professor of Electrical Engineering at University College Dublin and director of the Electricity Research Centre with research interests in power systems, control theory and biomedical engineering. 